\title{
CYCLIC TESTS ON THIN MASONRY VAULTS STRENGTHENED THROUGH COMPOSITE REINFORCED MORTAR
}

\author{
N. GATTESCO ${ }^{1}$, I. BOEM ${ }^{2 *}$ \\ ${ }^{1}$ Department of Engineering and Architecture, University of Trieste \\ Piazzale Europa 1, Trieste, Italy \\ e-mail: gattesco@units.it \\ ${ }^{2}$ Department of Engineering and Architecture, University of Trieste \\ Piazzale Europa 1, Trieste, Italy \\ e-mail: boem@dicar.units.it (*corresponding author)
}

Keywords: masonry, seismic retrofitting, composite materials, thin vaults, experimental tests

\begin{abstract}
The paper deals with the strengthening of thin masonry vaults by means of a CRM (Composite Reinforced Mortar) strengthening technique based on Glass Fiber-Reinforced Polymer (GFRP) meshes embedded in a $30 \mathrm{~mm}$ thick mortar matrix, applied at the vault extrados or intrados and connected to the masonry abutments through steel bars and GFRP elements. The experimental campaign concerned quasi static cyclic tests performed on four full-scale samples, supporting their self-weight only and subjected to uniform horizontal transversal loading. The results of the tests are described in terms of crack pattern, failure mode and load-displacement graphs, referring both to the horizontal displacement monitored at the crown section and to the sliding at the spring sections. High improvements in terms of both resistance and displacement capacities emerged in respect to the plain masonry and the connection with the abutments resulted fundamental for ensuring the reinforcement effectiveness.
\end{abstract}

\section{INTRODUCTION}

The presence of vaults in traditional masonry buildings of the European architectural heritage is very frequent, with variations that differ for the historical period and the geographical ambit [1]. Among the different typologies, thin vaults, namely the brick "in folio" vaults, made of solid bricks laid flatly in a single layer, characterize several historical buildings in Central and Southern Italy [2]. They concern, typically, barrel vaults, cloister vaults and groin vaults and they are used in flooring, ceilings, covering churches aisles, staircases. Actually, the structure construction starts with the progressive bricks overhang to form the abutments of the vault then a sequence of bricks arranged in flat are placed in order to provide the wanted shape (Figure 1a). These elements can be either load-bearing structures, filled with disaggregated material, on which the upper floor insist, or secondary elements constituting the ceiling of a room or other spaces and carrying their own weight only. In this latter case, due to the very high slenderness, the vaults have a high vulnerability to accidental actions and, in particular, to earthquakes [3] - Figure 1b,c, so that strengthening interventions are needed. 


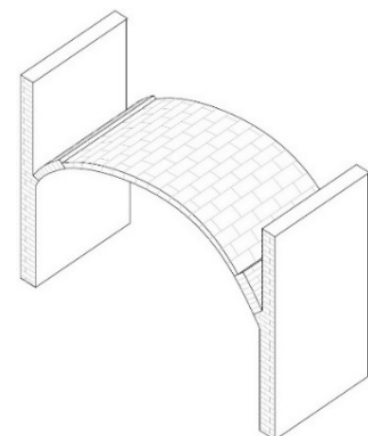

(a)

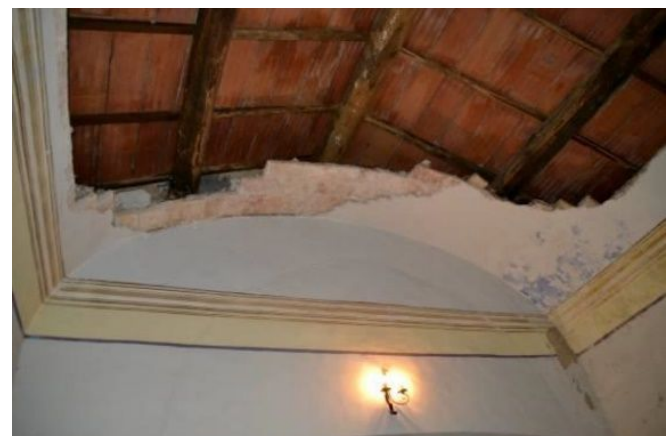

(b)

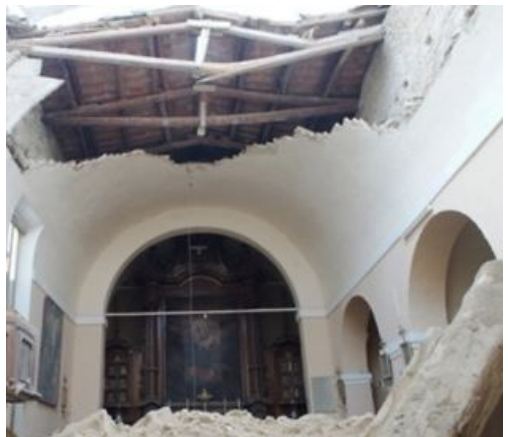

(c)

Figure 1: Brick in folio masonry vaults: (a) typical configuration and examples of vault failure occurred (b) in the St. Egidio's Church of Guardea, Italy [2] and (c) in the Capuchins' Church of Urbino, Italy (ifg.uniurb.it)

In the past, the jacketing with steel reinforced concrete has been extensively used to improve the resistance and stiffness of the unreinforced vaults, but durability and compatibility drawbacks led to the use of more suitable strategies for the application to historical assets. For example, the introduction of post-tensioned steel ties [4] or the construction of additional layers of brickwork and mortar on the extrados [5]-[6] proved to be effective intervention strategies. Moreover, the coupling of non-corrosive reinforcements (glass or carbon fibers, PBO, stainless steel) with inorganic matrices (including mortars based on natural lime) is gradually becoming a common practice [7]-[9].

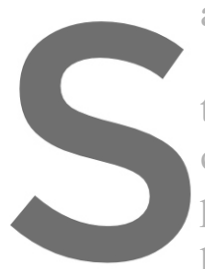

In this ambit, the aut technique based on the coating with GFRP previous tests concenned full-scale masonry batr paper reports original nesults concerning a r
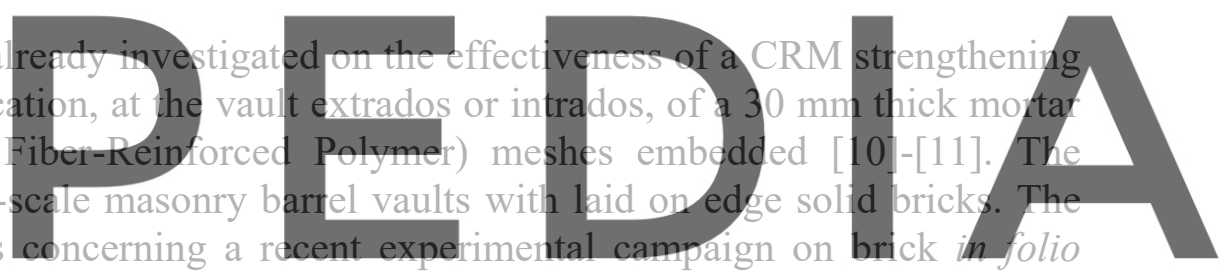
masonry vaults; a particular attention was devoted to the connection of the CRM layer with the

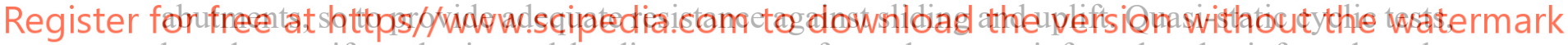
based on uniform horizontal loading, were performed on unreinforced and reinforced vaults built on masonry abutments. Both the reinforcement applied at the extrados and at the intrados were considered. The results are presented, compared and discussed in the paper in terms of crack pattern, failure mode and load-displacement graphs.

\section{SAMPLES CHARACTERISTICS}

The samples concern masonry barrel vaults made of solid bricks, having a rise-radius ratio $f / r=0.5$, with radius $r=2275 \mathrm{~mm}$, width $w=770 \mathrm{~mm}$ and thickness $t=55 \mathrm{~mm}$ (Figure 3). The compressive strength of the bricks was $f_{c, b}=16 \mathrm{MPa}$, that of the lime mortar $f_{c, m}=3 \mathrm{MPa}$. Four samples were tested: one concerned unreinforced masonry (vtNR), one reinforced masonry with the CRM at the extrados (vtRE) and two at the intrados (vtRI and vtRI+).

The CRM strengthening technique consists in the application of a $30 \mathrm{~mm}$ thick layer of mortar (mean compressive strength $f_{c, c}=7 \mathrm{MPa}$, Young modulus $E_{c}=14 \mathrm{GPa}$ ) with GFRP meshes embedded. To improve the adhesion to the substrate, a scratch coat was applied in samples vtRE and vtRI. Differently, in sample vtRI+, a pre-existing layer of mortar, $15 \mathrm{~mm}$ thick (mean compressive strength $f_{c, p}=5 \mathrm{MPa}$ ), was applied so to represent the cases where the 
removal of the existing plaster is unable without the vault damaging and it is therefore preferable to overlay the CRM; the surface was bush-hammered before the CRM application.

The GFRP mesh was produced by twisting the long glass fibers in one direction across the wires in the perpendicular direction, in which the fibers were maintained straight. The wires were coated with a thermo-hardening resin (vinyl ester epoxy and benzoyl peroxide as catalyst). The mesh had a $66 \times 66 \mathrm{~mm}^{2}$ grid pitch, with a fiber cross area of $3.8 \mathrm{~mm}^{2}$ in each wire. The twisted fibers wires had a mean tensile strength of $4.5 \mathrm{kN}$, with stiffness $264 \mathrm{kN}$, while the tensile strength of the straight fibers wires was $5.6 \mathrm{kN}$, stiffness $296 \mathrm{kN}$. In the vault samples, the orientation of the twisted fibers wires followed the arch direction.

In the vaults reinforced at the intrados, L-shaped GFRP connectors (6 per square meter, $7 \times 10 \mathrm{~mm}^{2}$ cross section) were applied by insertion into holes in masonry (12 mm diameter) and injected with vinylester epoxy resin. Square parts $\left(165 \times 165 \mathrm{~mm}^{2}\right)$ of GFRP mesh $\left(33 \times 33 \mathrm{~mm}^{2}\right.$ grid pitch) were introduced to improve the anchorage of the connectors in the mortar layer.

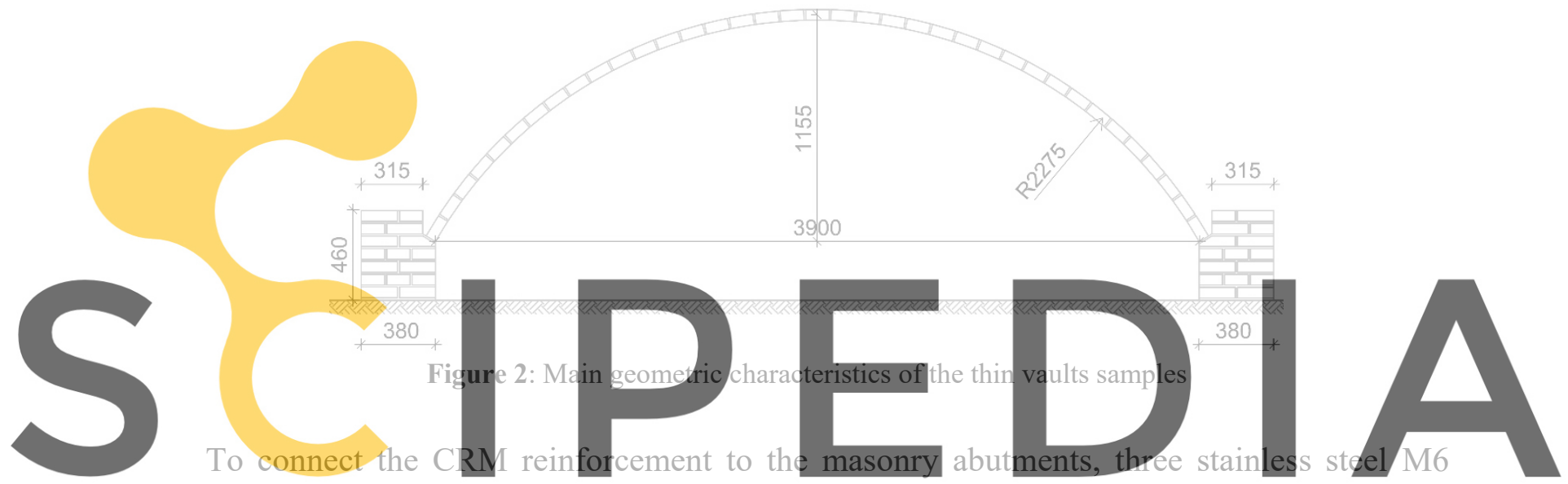
threated bars, $260 \mathrm{~mm}$ spaced, were applied at each end (Figure 3). Each bar was injected in

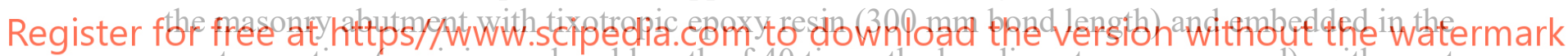
mortar coating (a minimum bond length of 40 times the bar diameter was ensured), with a nut applied at the end. Moreover, in cases concerning CRM applied at the intrados, the external couples of L-shape GFRP connectors perpendicular to the vault surface were deeply injected in the masonry abutments (Figure 3b).
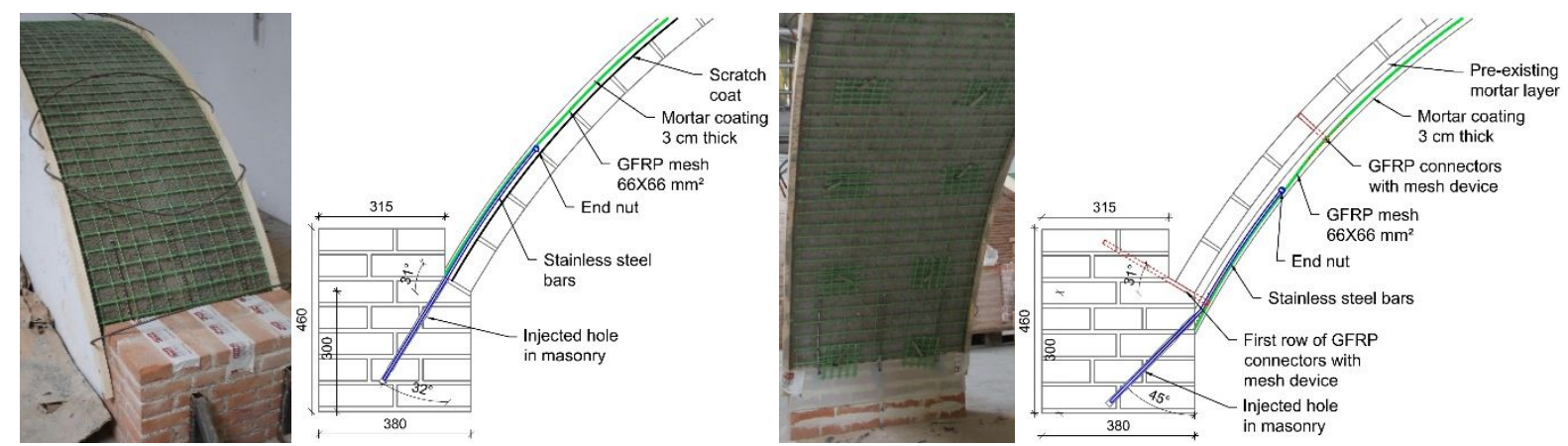

Figure 3: Arrangement of the CRM connection with the abutments for samples reinforced (a) at the extrados and (b) at the intrados 


\section{TEST SETUP}

The test setup (Figure 4a) was aimed to reproduce a uniform transversal load pattern representing the effect of the horizontal inertial forces induced by an earthquake on thin masonry vaults supporting their own weight only.

Quasi-static cyclic tests were performed: forces of identical magnitude and direction were applied at eight different points along the vault length, equally spaced, through pinned frame systems installed at the two halves of the vault and supported by sliding guides. The horizontal load was modulated through two hydraulic actuators applied at the opposite sides of the contrast structure and activated by a hand pump. Flow control valves permitted loading, unloading and the inversion of the loading direction.

The steel apparatus was designed adequately stiff, so to assume negligible its deformation in respect to that of the sample; loading cells and potentiometer transducers allowed the realtime monitoring of the load displacement story. More details were reported in [1].

It is observed that, due to the thinness of the vault, the vertical forces transmitted by the loading arms, induced by their weight, can modify significantly the vault stress state, especially in the early stages of the tests, when the horizontal load is low. Thus, the loading arms were hanged on the upper beams of the contrast frame through steel cords equipped with a preloaded tension spring at the upper end (Figure 4b). The initial elongation of each spring was calibrated so to completely counteract the vertical load transmitted to the vault. Similarly, also the pinned frame systems for the load distribution were hanged to avoid friction on the sliding guides.

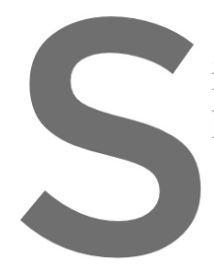

It is worth to note tha is negligible, since the length was at least 950
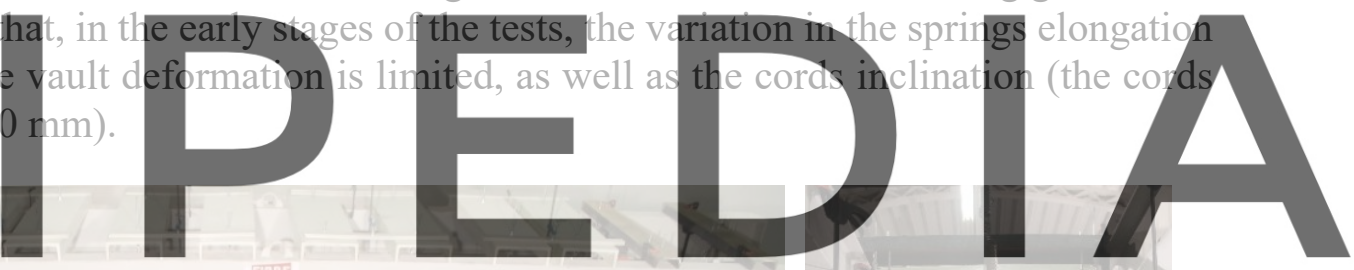

Register for free at https//www.scipedia.com to download the version without the watermark

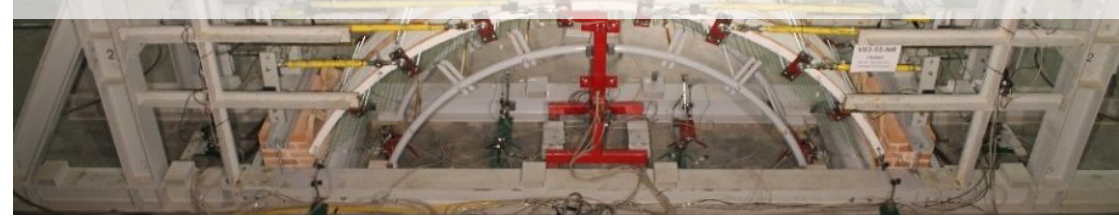

(a)

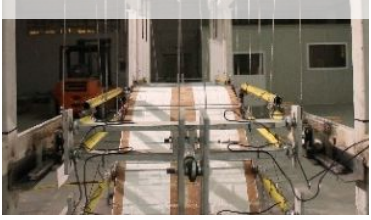

(b)

Figure 4: Test setup for the vaults: (a) global view and (b) detail of the hanging system

\section{EXPERIMENTAL RESULTS}

During the tests, horizontal cracks opened at the intrados or extrados, due to the flexural tensile failure of the masonry or of the mortar coating. The crack patterns of the vaults are schematized in Figure 5a-Figure 8a, distinguishing cracks formed for the two opposite loading directions (red and blue colors in agreement with the load direction).

Actually, in the unreinforced vault vtNR (Figure 5a,b), the cracks were localized in few sections. At first, in the negative loading direction, three cracks opened in the left vault side: 
one at extrados, in an haunch section (Figure 5c) and two at the intrados, at the skewback and near the keystone (Figure 5d). Then, when the loading direction was inversed, one crack at the extrados (at right haunch - Figure 5c) and one at intrados, at the right skewback, formed. The presence of four hinges, in alternate position extrados-intrados, was thus achieved and the vault failure mechanism activated. The maximum load, $F_{h, \max }$, equal to $0.55 \mathrm{kN}$, was attained in correspondence of very small horizontal displacement at the crown section $\delta_{h K}(<1 \mathrm{~mm})$.

Differently, in the reinforced samples, once four cracks formed in alternate position intradosextrados (typically, at the two skewback sections and at two opposite haunch sections), the load was maintained and even slightly increased. This was due to the presence of tensile resistant elements such as the GFRP mesh and the connection bars with the abutments, which provided additional bending resistance to the reinforced masonry sections. At the increasing of the vault deformation, a diffuse cracking of the mortar coating generally occurred and several cracks formed on the masonry side.

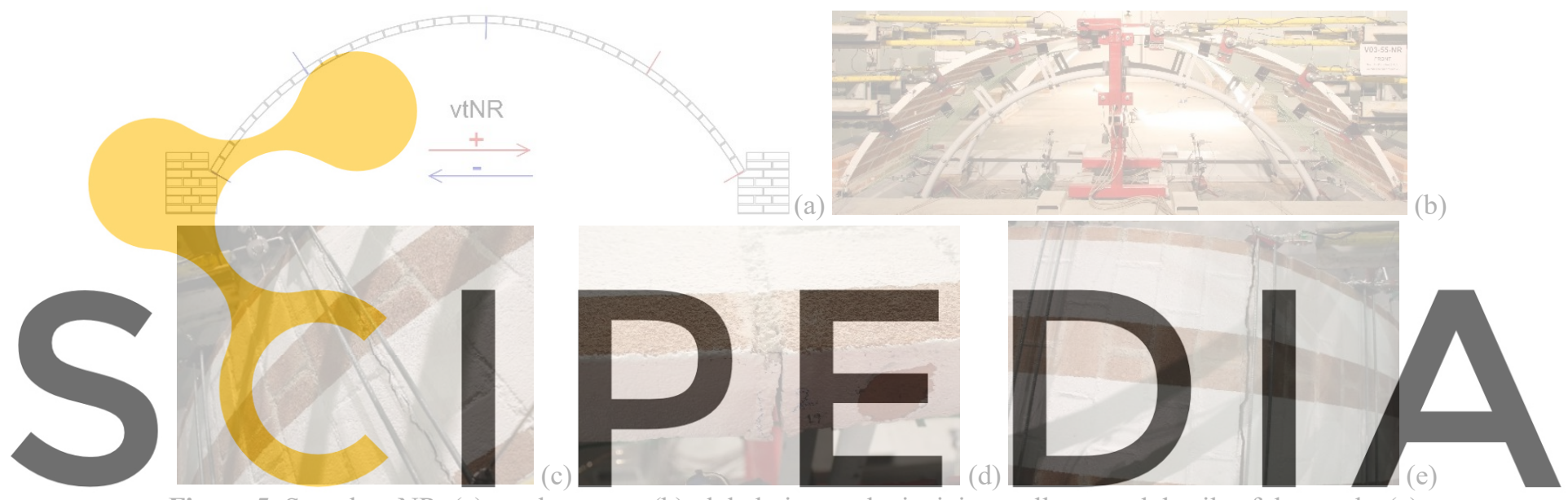

Figure 5: Sample vtNR: (a) crack pattern, (b) global view at the incipient collapse and details of the cracks (c) at Register for free at https//WwW.Scipedia.com to download the version without the watermark

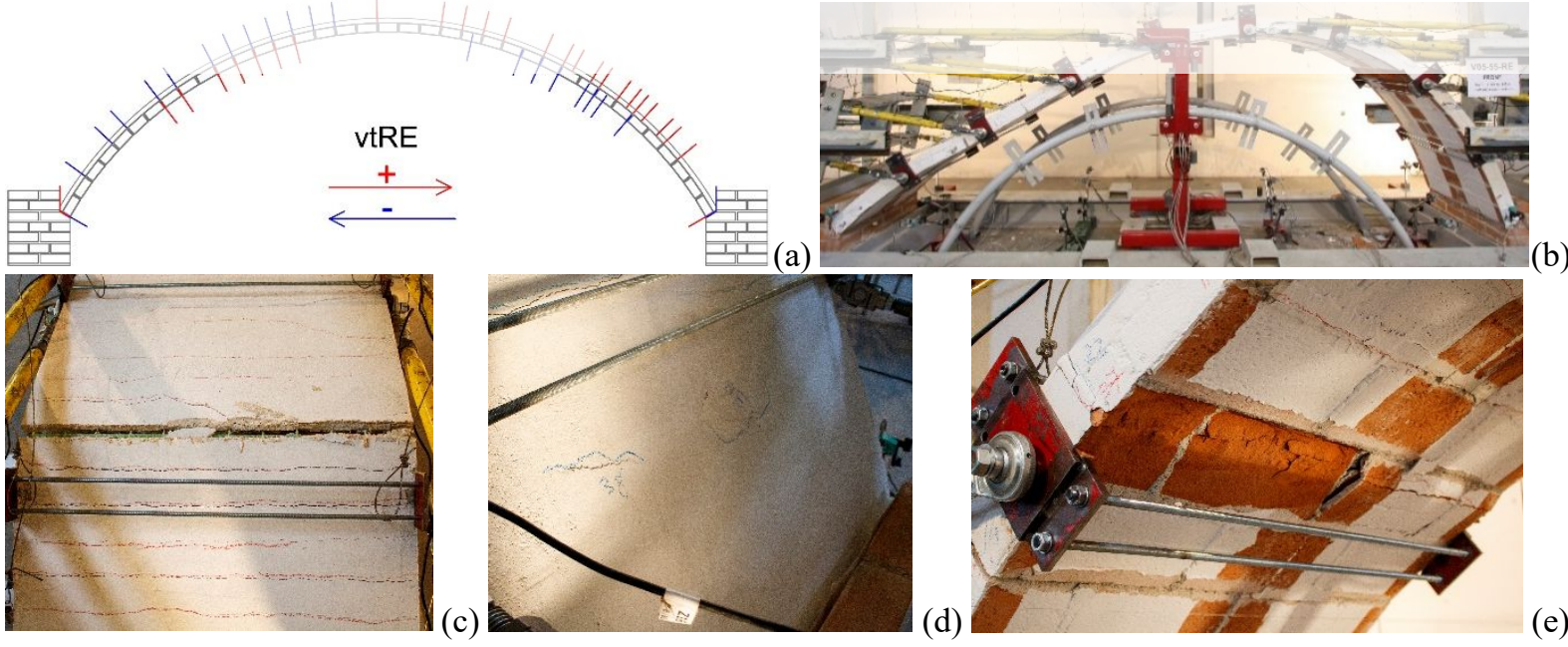

Figure 6: Sample vtRE: (a) crack pattern, (b) global view at the incipient collapse and details (c) of the cracks and GFRP mesh rupture at the extrados of the right haunch, (d) of the mortar local cracking in correspondence of the connection steel bars and (e) of the compressive local failure of some bricks at the intrados of the left haunch 
Sample vtRE (Figure 6a,b) reached a maximum load $F_{h, \max }=+11.8 \mathrm{kN}$ at $\delta_{h K}=115.5 \mathrm{~mm}$. The vault collapsed when the rupture of the GFRP wires disposed along the vault occurred at the right haunch section (Figure 6c). During the test, starting from about $\delta_{h K} \cong \pm 80 \mathrm{~mm}$, some mortar local damage in the vicinity of the end nut of some steel bars was noted, as likely caused by the occurrence of some slip in the coating (Figure 6d). The bricks compressive failure at the haunches was also observed at very high displacements $\left(\delta_{h K}>110 \mathrm{~mm}\right)$ - Figure $6 \mathrm{e}$.

Sample vtRI (Figure 7a-d), attained to $+7.3 \mathrm{kN}$ (at $\delta_{h K}=+19.6 \mathrm{~mm}$ ) in the positive direction and then approximately maintained the load, while in the negative, once reached $-8.2 \mathrm{kN}$ (at $\delta_{h K}$ $=-27.9 \mathrm{~mm}$ ) the load gradually decreased. Some mortar damaging in the vicinity of the GFRP connectors at skewbacks emerged from about $\delta_{h K} \cong \pm 45 \mathrm{~mm}$. Moreover, at about $\delta_{h K} \cong \pm 70$ $\mathrm{mm}$, a conic splinter in correspondence of some steel bars, close to the end nut, evidenced the partial extraction from the coating (Figure 7c). Some inward slip was noted at the spring sections (Figure 7e); while no evident outward slips emerged (Figure 7f).

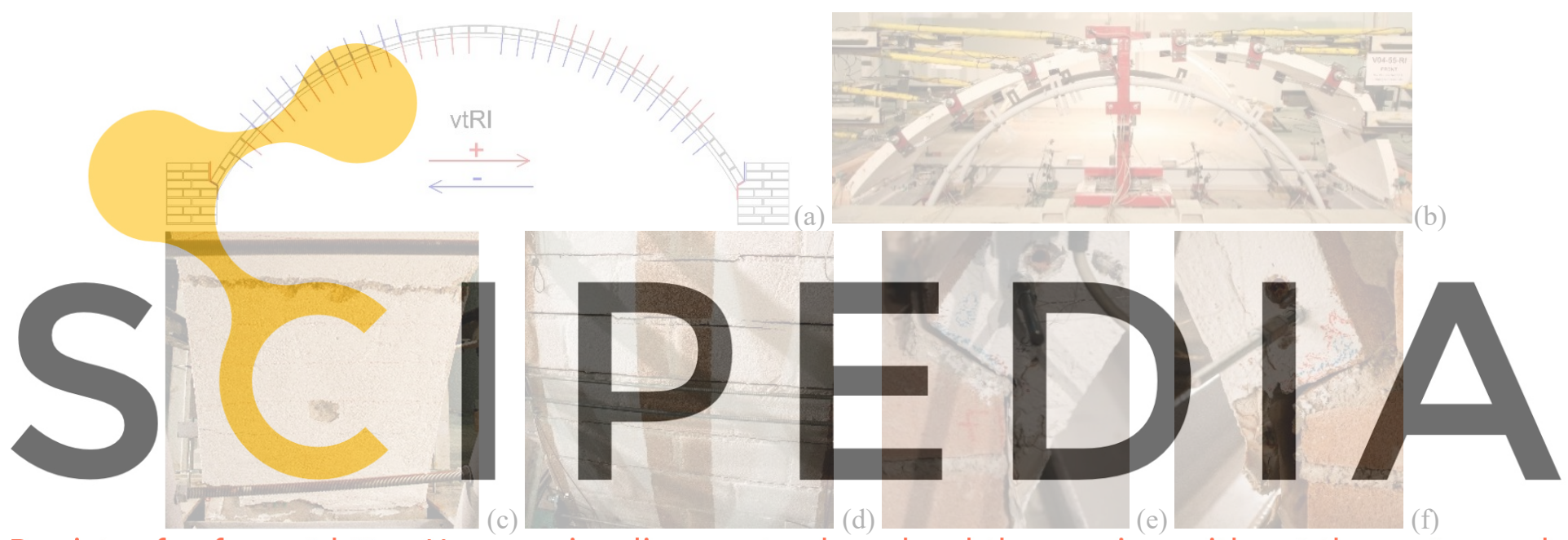

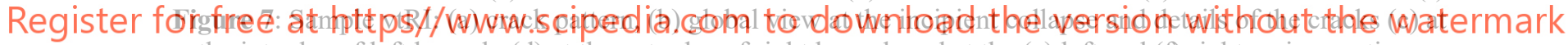
the intrados of left haunch, (d) at the extrados of right haunch and at the (e) left and (f) right spring sections

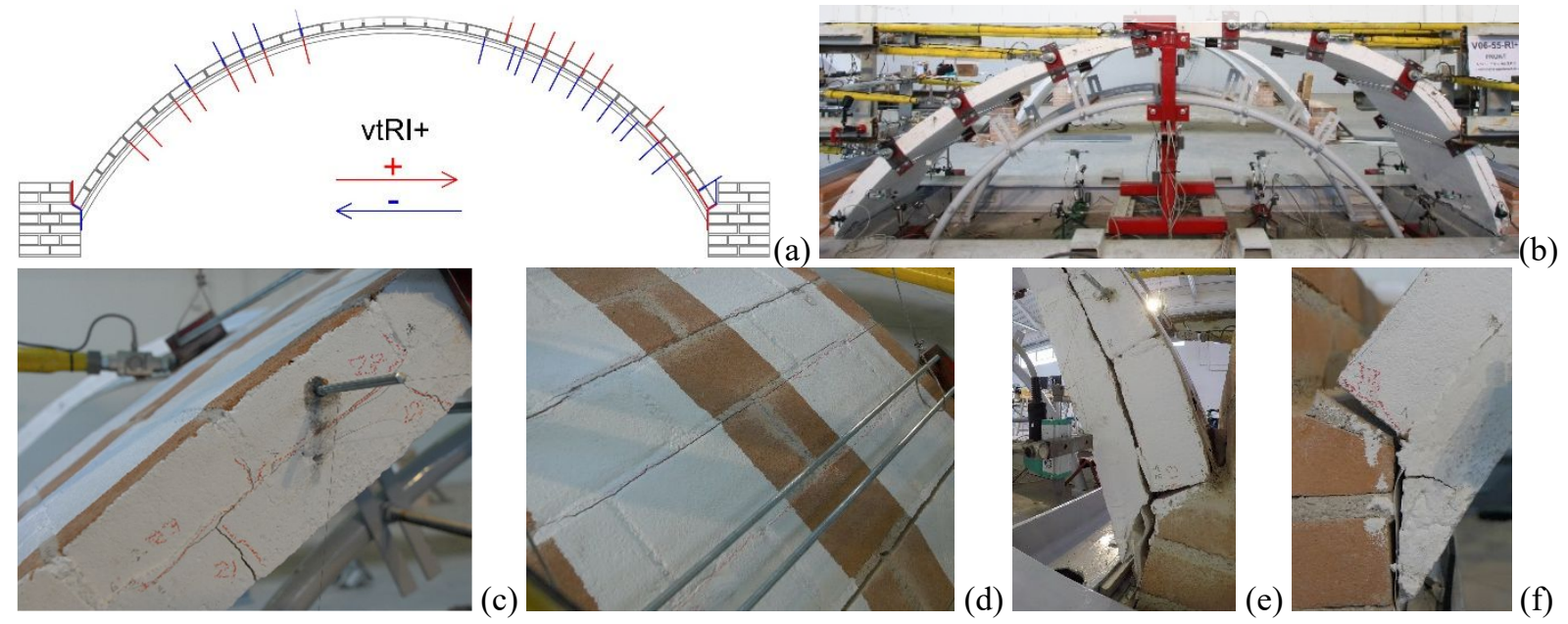

Figure 8: Sample vtRI+: (a) crack pattern, (b) global view at the incipient collapse and details of the cracks (c) at the intrados, left haunch, and (d) at the extrados, right haunch, (e) of the mortar detachment from the masonry at the right end and (f) of the inward slip at the left spring section 
Sample vtRi+ (Figure 8a-d) attained to $+13.1 \mathrm{kN}$ (at $\delta_{h K}=+39.0 \mathrm{~mm}$ ) and to $-10.5 \mathrm{kN}$ (at $\delta_{h K}=-21.0 \mathrm{~mm}$ ). As the deformations increased, detachment surfaces formed between the preexisting mortar layer and the masonry substrate (Figure 8c); the most relevant emerged at about $\delta_{h K}=+40 \mathrm{~mm}$, around the right skewback (Figure 8e) and induced a significand load decrease in both directions. Some inward slip was also noted at the spring sections (Figure 8f).

\section{ANALYSIS OF RESULTS}

The results of the tests on reinforced masonry vaults are plotted in the graphs of Figure 9$11 \mathrm{a}$, in terms of capacity curves representing the trend of the global horizontal load, $F_{h}$, at the varying of the mean horizontal displacement monitored at keystone $\delta_{h K}$. The capacity curve of the unreinforced masonry sample was omitted, due to the very low performances in terms of both resistance and displacements before collapse $\left(F_{h, \max }=0.55 \mathrm{kN}\right.$, with $\left.\delta_{h K}<1 \mathrm{~mm}\right)$.

All the reinforced samples achieved significantly high performances in respect to the plain vault, both in terms of horizontal load and displacement capacities. In particular, the resistance ratio resulted about 21.5 for vtRE and 14.9 for vtRI.

The comparison between vtRI+ and vtNR is not proper (an unreinforced masonry vault with a pre-existing mortar layer should be considered). However, vtRi and vtRI+ can be compared: the presence of the pre-existing layer of mortar, reasonably lead to and higher resistance $(+60 \%)$, due to the thicker cross section, but a premature detachment of the mortar from the masonry substrate, related to the higher stress state, can compromise the reinforcement

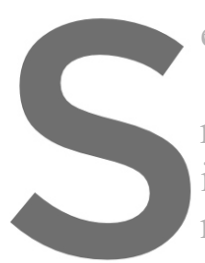
effectiveness (reduced ductility).
Reasonably, a progressive strength and stiffn
reinforced samples would occur in repeating
irreversible damage accumulation related to the
masonry and in the mortar coating.

The trends of the horizontal load at the varying of the mean tangential displacements $\delta_{h s}$ monitored at the skewback sections are plotted in Figure 9-11b. It is observed that in sample Register for free at htgps/fwww. scipediacom to downl gad the version without the watermark direction and reached about $+20 \mathrm{~mm}$ at the left vault end in correspondence of the peak load. In both loading directions, the outward sliding resulted more limited due to the constraint provided by the masonry abutments; thus, the graphs $F_{h, \max }-\delta_{h s}$ are asymmetric. In sample vtRI, the inward slides attained to about $\pm 15 \mathrm{~mm}$ at the last cycles (Figure 10b); while in sample $\mathrm{vtRI}+$ (Figure $11 \mathrm{~b}$ ) ranged between $-8.5 \mathrm{~mm}$ and $+17 \mathrm{~mm}$ at peak loads. Then, sliding reached $-15.5 \mathrm{~mm}$ and $+25.5 \mathrm{~mm}$; also comparable outward slides emerged in the last cycles.

The configuration with the reinforcement applied at the extrados, vtRE, resulted more effective than that with the reinforcement applied at the intrados, vtRI. In this regard, it is observed that the monitored inward sliding at the spring sections determined, in vtRE, an increasing of the bending at the extrados along the vault, with a better exploitation of the GFRP mesh resisting contribution in tension, as evidenced by the final rupture of the mesh wires. Differently, in vtRI, the inward slide induced a decrease of the bending stress along the vault intrados; in fact, the mesh failure did not occur. However, the resistance increase in respect to the unreinforced configuration is significant, thus the investigated configuration is adequate.

In general, the appropriate design of the connection of the CRM layer with the abutments, (both in resistance and in stiffness), is fundamental for assuring the effectiveness of the 
strengthening intervention and avoiding that excessive, premature local movements at the ands compromise the reinforcement contribution.
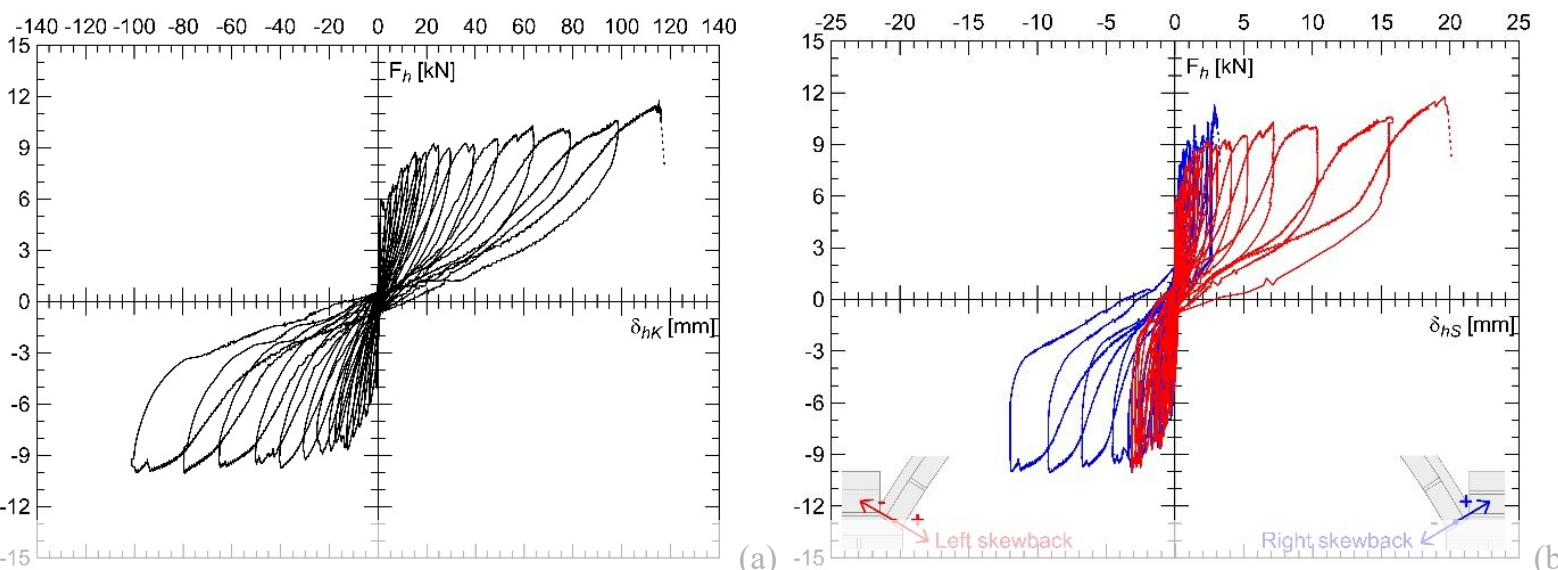

Figure 9: Sample vtRE - trend of the horizontal load at the varying (a) of the horizontal displacements at the crown section and (b) of the tangential displacement at the skewback sections
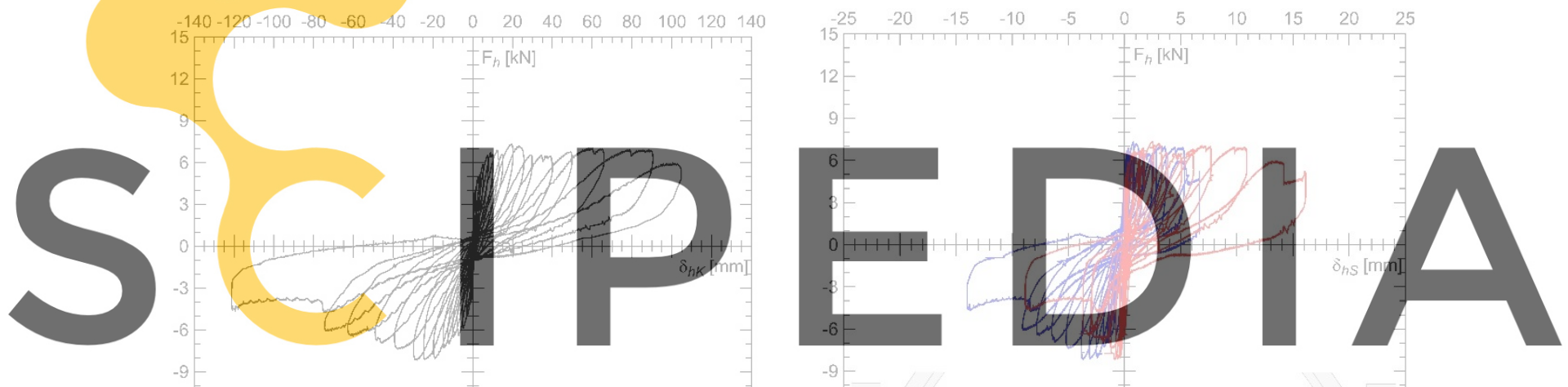

Register for free at https//www.scipedia.com to dowinload the version without the watermark

Figure 10: Sample vtRI - trend of the horizontal load at the varying (a) of the horizontal displacements at the crown section and (b) of the tangential displacement at the skewback sections
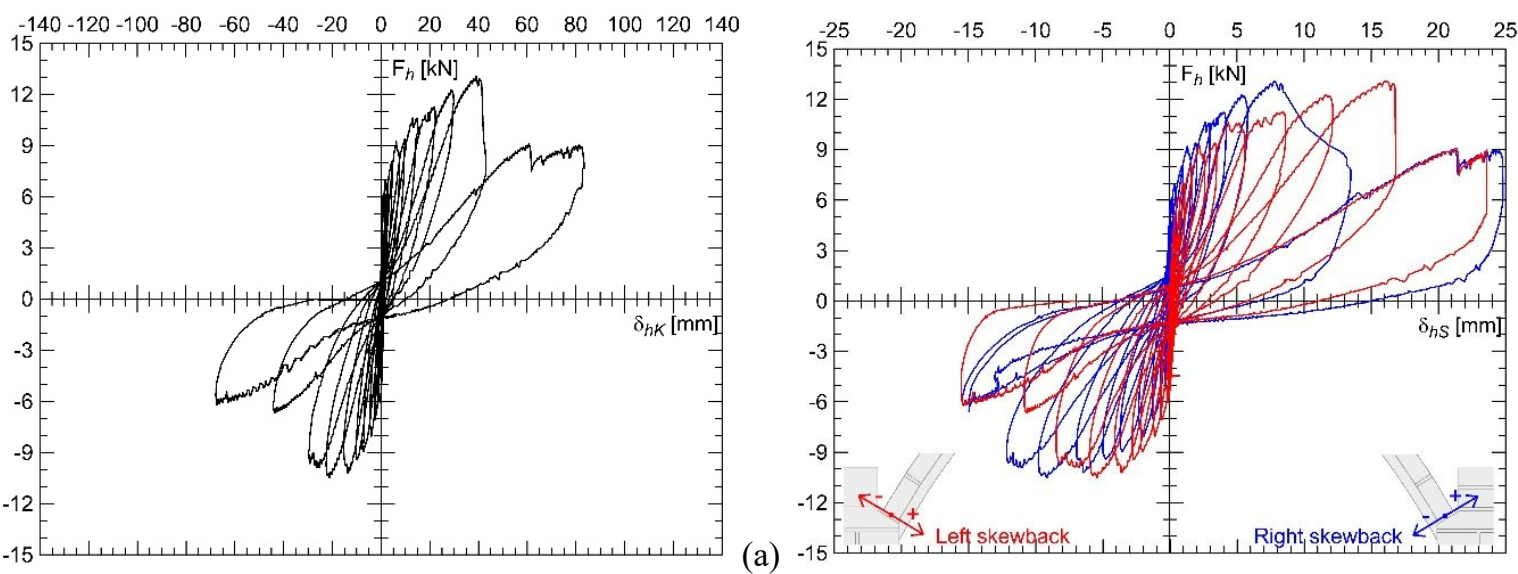

Figure 11: Sample vtRI+ - trend of the horizontal load at the varying (a) of the horizontal displacements at the crown section and (b) of the tangential displacement at the skewback sections 


\section{CONCLUSIONS}

The paper reports original results of a recent experimental campaign on thin masonry barrel vaults strengthened with CRM system. It concerned quasi static cyclic tests performed on fullscale samples subjected to horizontal transversal loading, so to reproduce the effects of inertial forces induced by an earthquake on thin vaults supporting their own weight only.

The tests setup is described in the paper, evidencing the strategy adopted to avoid parasitic stresses on the samples, induced by the loading system. The main samples features are reported, focusing on the strategy adopted to connect the reinforced layer to the masonry abutments, based of steel bars and GFRP L-shape connectors.

The results of the tests are described, detailing the crack patterns and the different failure modes of the four tested samples: one unreinforced (vtNR), one with the CRM applied at the extrados (vtRE) and two with the CRM at the intrados (vtRI and vtRI+, in which the presence of a pre-existing mortar layer was also accounted). The experimental curves of the reinforced samples, representing the trend of the horizontal load at the varying of both the horizontal displacement at the crown section and of the sliding at the spring sections, were plotted and compared.

It emerged that the GFRP mesh is able to limit the separation by rotation of the faces of cracked sections, allowing instead a widespread mortar cracking and delaying the activation of the collapse mechanism. High improvements in terms of both resistance and displacement capacities were obtained in respect to the plain masonry: the resistance ratios resulted about

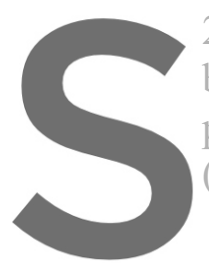
21.5 timer for vtRE and

between the pre-existing premature detachment (ductility).

The connection with the abutments resultec,
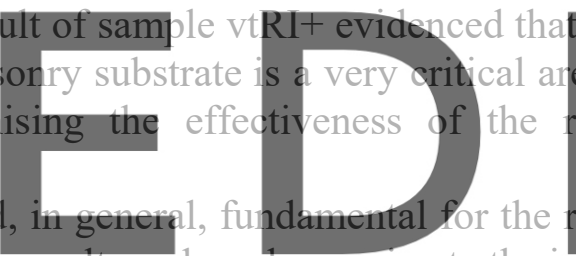

effectiveness, contrasting the free rotation at the vaults ends and opposing to the inward sliding.

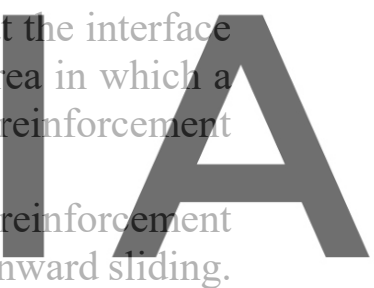

It is however observed that the designed connection configurations partially constrained these

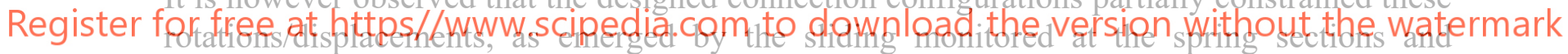

evidenced by some mortar local damage in the vicinity of some steel bars and of some GFRP connectors.

Numerical investigations are in progress, so to simulate the experimental tests and perform parametric analysis on more configurations. Pull-out characterization tests will allow to calibrate the actual behavior of both the GFRP L-shape connectors and the steel bars and also to evaluate the possible contribution of the bars in contrasting the inward sliding (dowel effect).

Acknowledgements. This paper is based on part of a research project financed by the composite engineering factory Fibre Net SpA, Pavia di Udine (UD), Italy. The authors wish also to thank Allen Dudine, Carlos Passerino and Andrea Miniussi for the useful help provided during the tests.

\section{REFERENCES}

[1] Brumana, R., Condoleo, P., Grimoldi, A., Landi, A.G. Shape and construction of brick vaults. Criteria, methods and tools for a possible catalogue. In: The International Archives of the Photogrammetry, Remote Sensing and Spatial Information Sciences, Volume XLII- 
5/W1 (2017). Geomatics \& Restoration - Conservation of Cultural Heritage in the Digital Era, 22-24 May 2017, Florence, I.

[2] Nunziata, A., Bianchini, N., D’Andrea, M., E., Serpe. Le volte in foglio e il sisma. Analisi delle chiese nell'area Umbro-Marchigiana. In: IV Convegno di Ingegneria Forense - VII Convegno su crolli, affidabilità strutturale, consolidamento, 14-16 September 2017, Milan, I (in Italian).

[3] Indirli, M., Kouris, L.A.S., Formisano, A., Borg, R.P., Mazzolani, F.M. Seismic Damage Assessment of Unreinforced Masonry Structures After The Abruzzo 2009 Earthquake: The Case Study of the Historical Centers of L'Aquila and Castelvecchio Subequo. International Journal of Architectural Heritage: Conservation, Analysis and Restoration (2013), 7(5), 536-578.

[4] Jurina, L. The reinforced arch: a new technique for strengthening masonry arches and vaults using metal tie bars. In: 16th National Congress of the C.T.A. (1997) Ancona, I.

[5] Capozucca, R., Analysis of thin composite masonry vaults. Masonry International (1997) 11(1): 19-25.

[6] Castori, G., Borri, A., Corradi, M. Behavior of thin masonry arches repaired using composite materials. Composites Part B: Engineering (2016) 87:311-321.

[7] Briccoli Bati, S., Rovero, L., Tonietti, U. Strengthening masonry arches with composite materials. Journal of Composite for Construction (2007) 11(1):33-41.

[8] Garmendia, L., Marcos, I., Garbin, E., Valluzzi, MR. Strengthening of masonry arches with

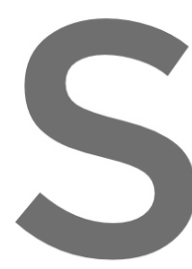
Textile-Reinfor

[9] Alecci, V, Focac brick masonry investigations.
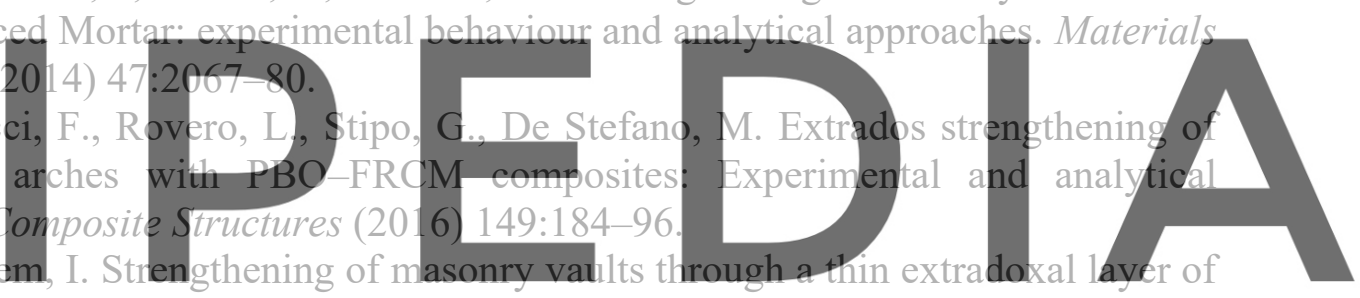

fiber reinforced lime mortar. In: 10th International Conference on Structural Analysis of

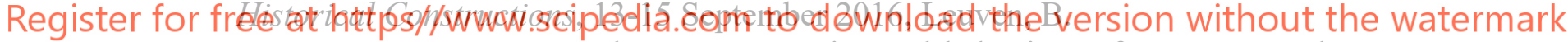

[11] Gattesco, N., Boem, I., Andretta, V. Experimental behaviour of non-structural masonry vaults reinforced through fibre-reinforced mortar coating and subjected to cyclic horizontal loads. Engineering Structures (2018) 172: 419-431. 